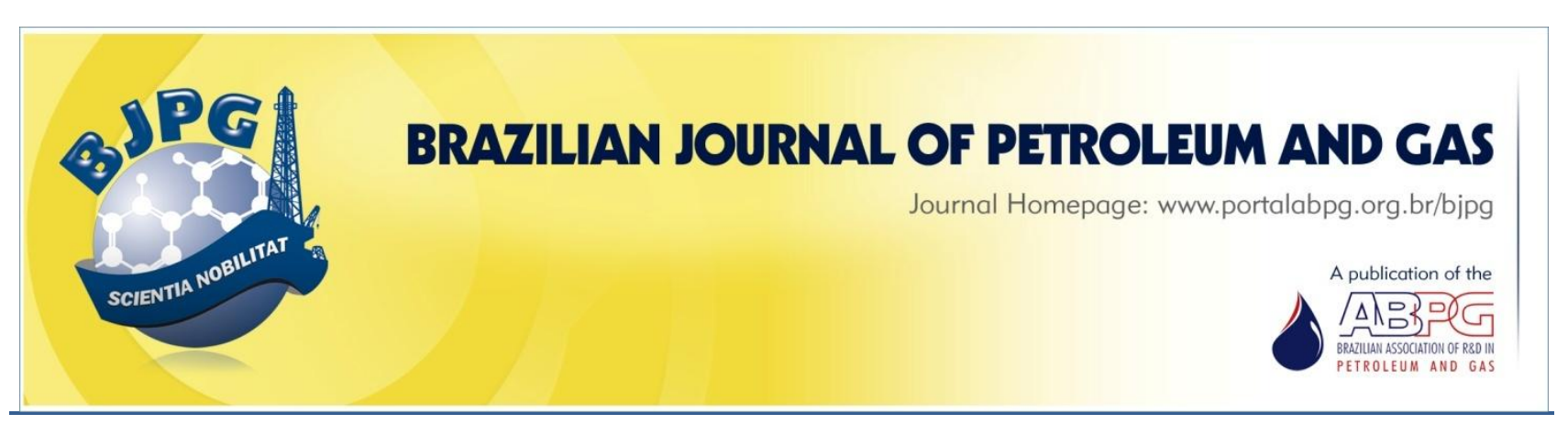

\title{
AUTOMATED METHODOLOGY FOR DETECTING BORDER IN CT-SCAN IMAGES OF NON-CIRCULAR ROCK SAMPLES
}

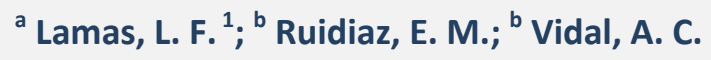 \\ ${ }^{a}$ Center for Superior Education Foz do Itajaí / Santa Catarina State University - CESFI/UDESC, Balneário Camboriú - SC - Brazil \\ ${ }^{b}$ Center for Petroleum Studies / University of Campinas - CEPETRO/UNICAMP, Campinas- SP - Brazil \\ Received: 30.07.2019 / Revised: 08.11.2019 / Accepted: 15.11.2019 / Published on line: 20.12.2019
}

\begin{abstract}
X-ray computed tomography, CT-scan, is a very important tool in special core analysis, because it allows the visualization of the interior of cores, providing information such as porosity, saturations, and changes on these parameters with time. CT-scan images are usually square, and contain information not only the core, but also parts of the core-holder, the water used to pressurize the system, and the rubbers that hold the cores in place. Software available to process these images are usually very expensive, or do not allow reasonable automation of the process of treating images. This paper proposes a simplified methodology to isolate the core in a CT image, allowing the processing of multiple images without the interference of the user. This methodology can be implemented easily in any computer language, it saves operation time, and reduces the risk of human error.
\end{abstract}

\section{KEYWORDS}

SCAL; CT scan; vugular rocks; reservoir engineering; Python

\footnotetext{
${ }^{1}$ To whom all correspondence should be addressed.

Address: Center for Superior Education Foz do Itajaí / Santa Catarina State University - CESFI/UDESC, Avenida Lourival Cesário Pereira, s/n, Edifício Alcides Abreu - Nova Esperança - Balneário Camboriú, Santa Catarina, Brazil ZIP Code: 88336-275 | Phone number: +55(47) 3398-6510 | e-mail: luislamas@bol.com.br doi:10.5419/bjpg2019-0023
} 


\section{INTRODUCTION}

Computer tomography (CT) is a very important tool in the special core analysis (SCAL), and it has been used since the 1980's (Honarpour, 1985). There are several advantages of using CT in comparison to other techniques. Among them is the fact that the analysis is not destructive. It can also be repeated during the test, meaning that changes in the internal structure (mineral precipitation and dissolution) and fluid saturations can be followed with high reliability.

X-ray is attenuated inside the rock. This attenuation is called radiodensity, which is a function of material density and chemical composition (Kak \& Slaney, 1988). Coreflooding experiments induce changes in both saturation and, especially in carbonates, in rock composition. For the reasons mentioned, the use of CT in the study of reservoir cores is very important.

3D pore characterization, 3D grain analysis, fracture analysis, multiscale imaging, and mineral analysis are some of the most recent and important applications of the X-ray tomography (Cnudde \& Boone, 2013).

Several authors propose methodologies to process CT data. Vidal Vargas (2015) proposed a methodology to remove the parts of the image that are not related to the core, determining the center and radius of the core inside the image. This image is used to calculations of average CT, allowing later calculations of porosity and fluid saturation.

Hall and Govert (2016) developed a workflow for processing raw whole core CT data. This workflow cleans, removes artifacts, and creates a digital model of the core. One important part of the algorithm proposed by Hall and Govert (2016) is the detection of the border of the core. This is important to ensure that all information outside the rock (rubber, pressurizing fluids, and coreholder) is excluded from the analysis. Generally, this border is circular, and its detection is straightforward.

A recurring problem of these algorithms is the fact that analysis of CT images can be dependent on the operator, and that algorithms, such as the one described by them, can also solve this issue.
This paper proposes a simplified methodology to isolate the core in a CT image, not dependent on the geometry of the core. Therefore, one can use a rock sample extremely heterogeneous without cylindrical geometry and still process multiple images without the interference of the user. This methodology is easily implemented using any computer language, saving operator's time, and reducing the risk of human error.

\section{METHODOLOGY AND APPLICATION}

The routine for image processing follows a standard procedure which is implemented manually, and is time consuming for longer cores or composite core material (Vidal Vargas, 2015). In a typical procedure, images need to be treated and switched, leading to loss of information from the DICOM format.

In this work, a highly vugular core was assembled inside a core holder. The rock sample was separated from the overburden fluid by a Viton sleeve.

The core holder was assembled according to Figure 1 and covered with a heating blanket and an injection pump to reach the experimental condition of $105.6^{\circ} \mathrm{C}$ and 150 bar. A vacuum pump was connected to evacuate the air and let nitrogen at the same condition of the experiment using the saturated core sample. Then, the first CT scan was carried out as the initial step for characterization. The second step was to connect the vacuum pump to remove the nitrogen and inject water previously heated and pressurized to saturate the core sample. Finally, the second CT scanning was carried out and the DICOM files were taken for processing using the Python routine.

Each slice of the image is saved as a DICOM file. This raw file is a metafile, which contains several pieces of information regarding the equipment, patient, and image data (a 512 × 512 matrix containing the $\mathrm{CT}$ value for each pixel). One must avoid compressing the image data to prevent the loss of information.

To implement the algorithm, the language Python $^{\circledR}$ was chosen. To process the DICOM file, the library Pydicom (2019) was selected, because it can extract the image data from the raw file easily. 


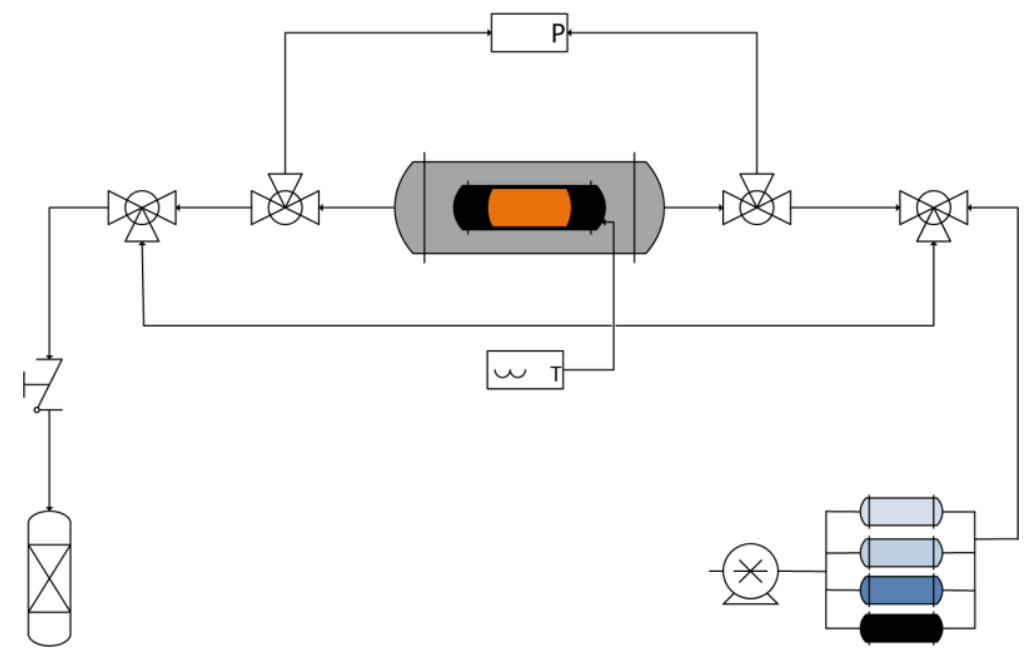

Figure 1. Description of the experimental apparatus.

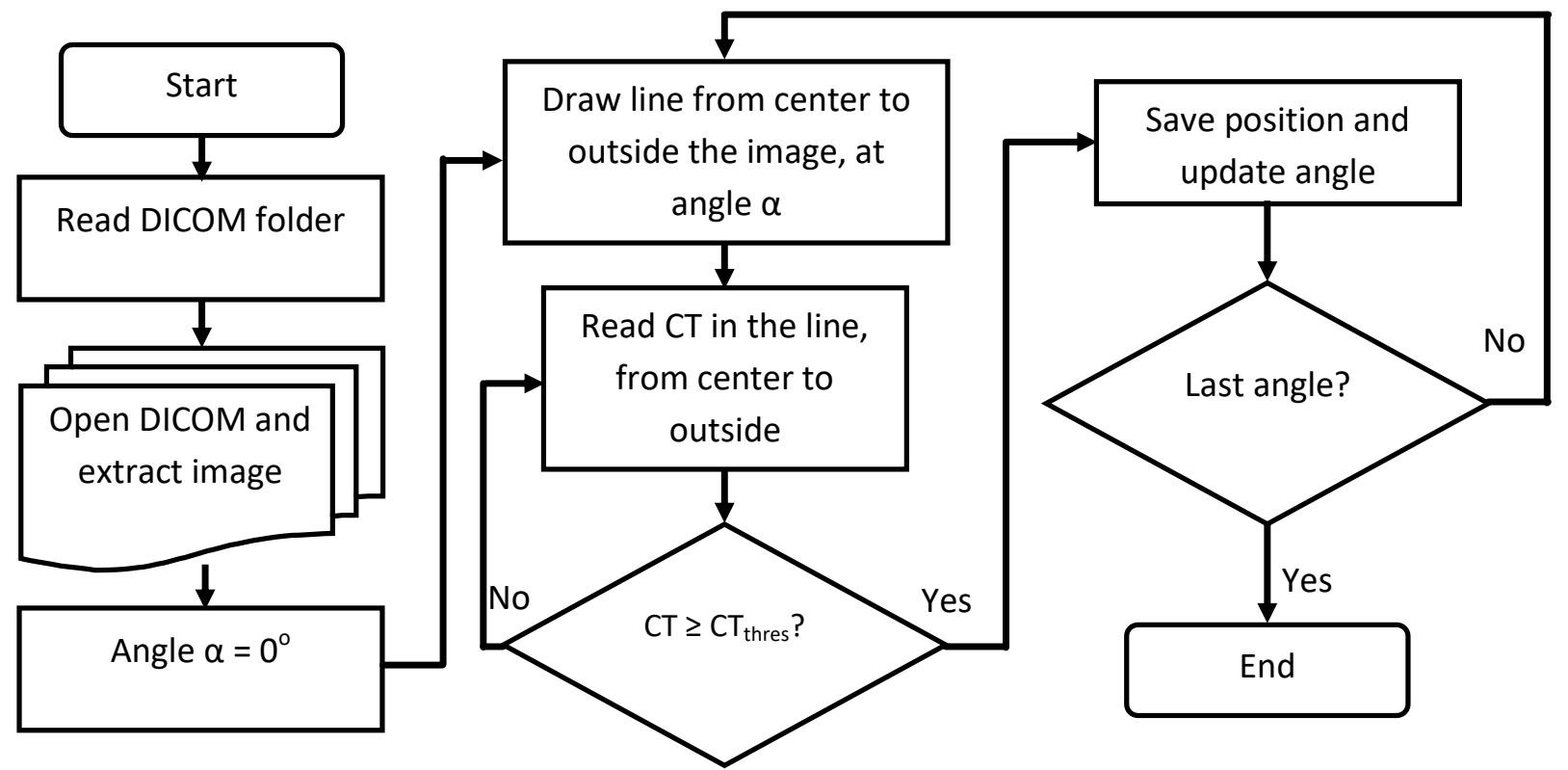

Figure 2. Algorithm to selection of border points.

Figure 2 shows the flow chart of the algorithm, which consists of drawing lines from the center of the image to the outer part of the image. When a threshold $\left(\mathrm{CT}_{\text {thres }}\right)$ value is achieved, it retains the point as a border point. The result of this algorithm is a list of points of the figure laying on the border.

From this list of border points, and the library matplotlib.path, it is possible to generate a polygon and check, for each point of the figure, whether it is inside or outside the polygon. All values of points outside the polygon are set to $\mathrm{NaN}$.

\section{RESULTS AND DISCUSSIONS}

Figure 3 shows some slices of the figure, to emphasize the fact that the geometry of the border of the core is not circular.

The yellow circle around the rock is the rubber. A very important step of this procedure is to make sure that the CT contrast of the rubber and the rock is high enough to be detectable. Figure 4 shows the line 255 of a random slice. 

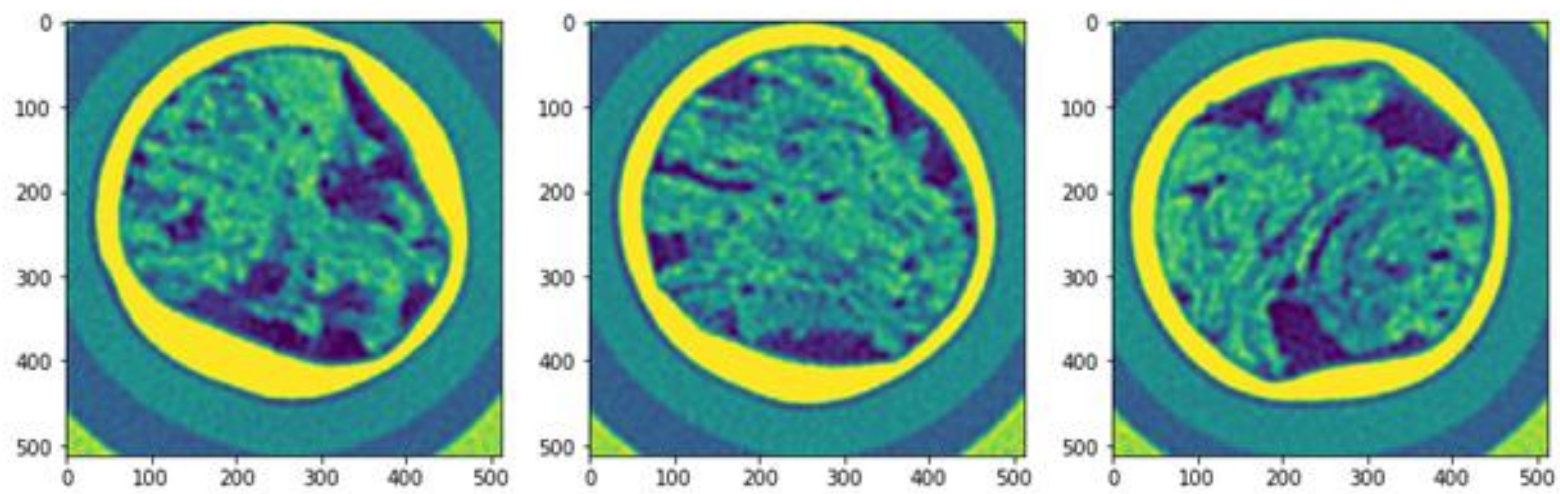

Figure 3. Examples of border geometry of the core.

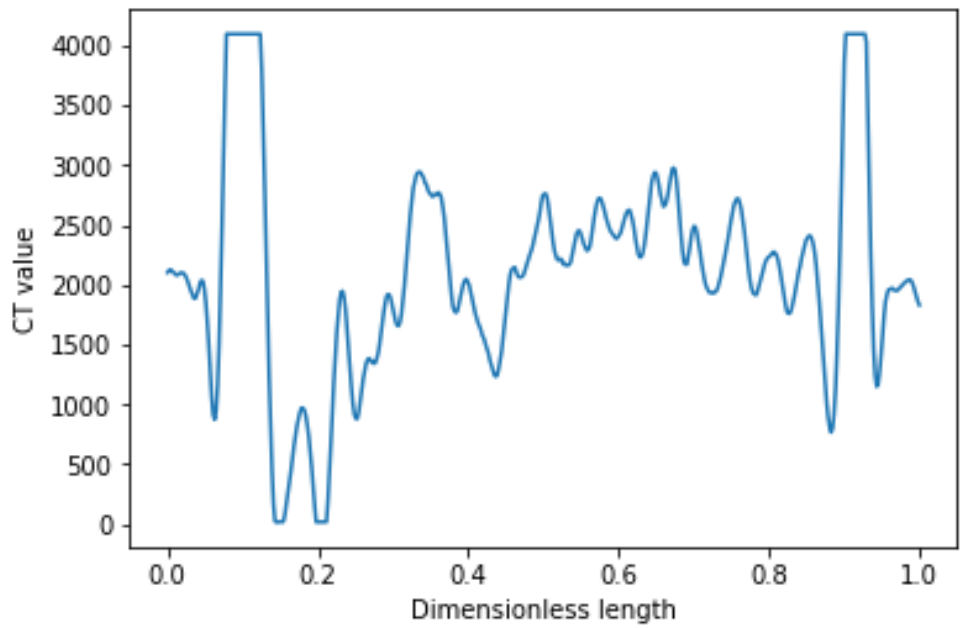

Figure 4. CT values in the central line of a random image.

It is possible to observe that the CT value is considerably higher in the rubber than that of inside the rock. Another important assumption is that the center of the image (position 255×255) always lays in the rock.

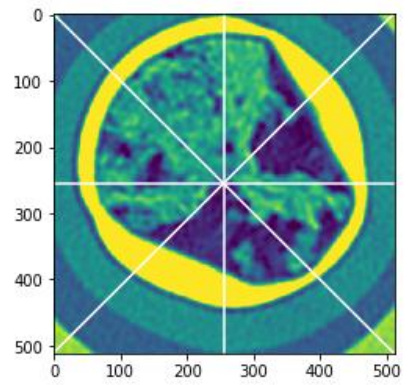

Figure 5. Lines drawn from the center to the edge of the figure to detect position of the border.
The procedure consists of, then, drawing lines from the center of the image to the outer part of the image, and when a threshold value is achieved, retaining the point as a border point. Figure 5 exemplifies the path of these lines.

The number of lines (or angles) is reflected on the quality of the final image. A large number of angles, however, can lead to a high computational time. Figure 6 shows these border points for 10, 15, 20 , and 30 border points.

From the list of border points and the library matplotlib.path, one can generate a polygon, and check, for each point of the figure, if it is inside or outside the polygon. All values of points outside the polygon are set to $\mathrm{NaN}$. It is possible to infer that the quality of the final image will be directly 

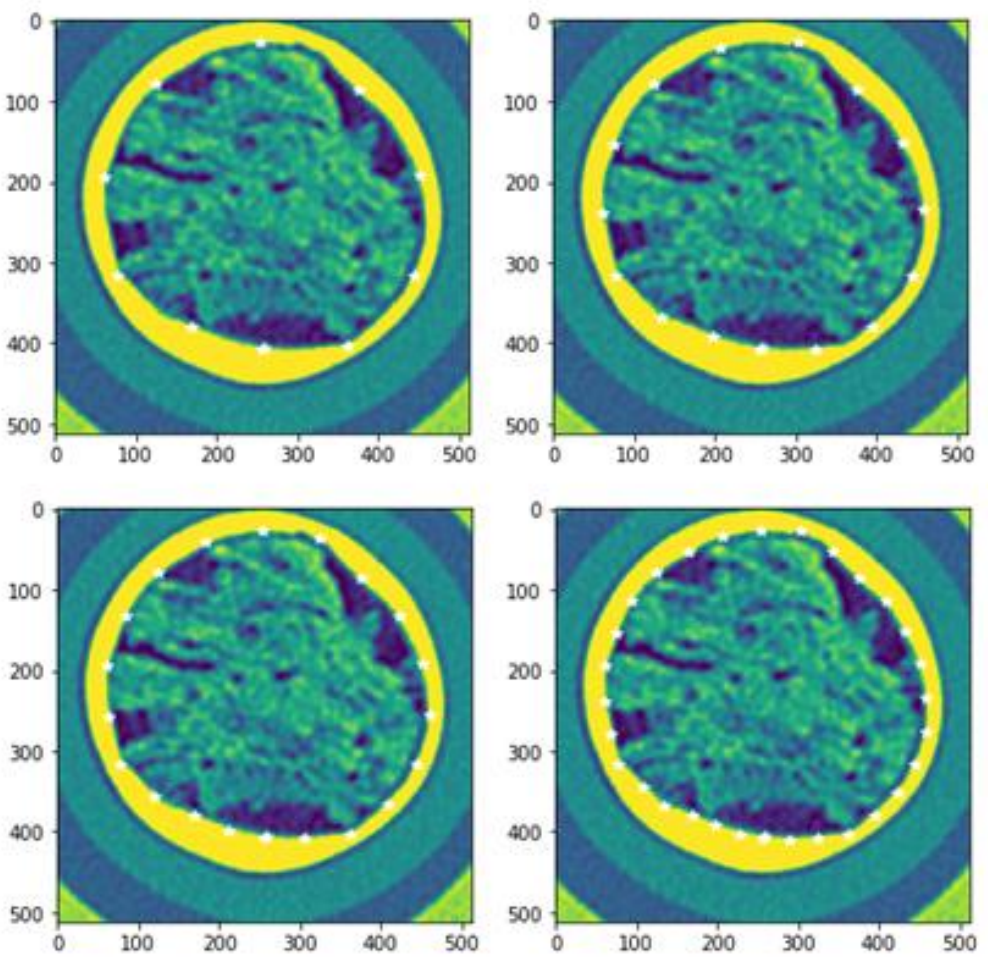

Figure 6. Border points detected in a sample image, considering 10, 15, 20, and 30 angles.
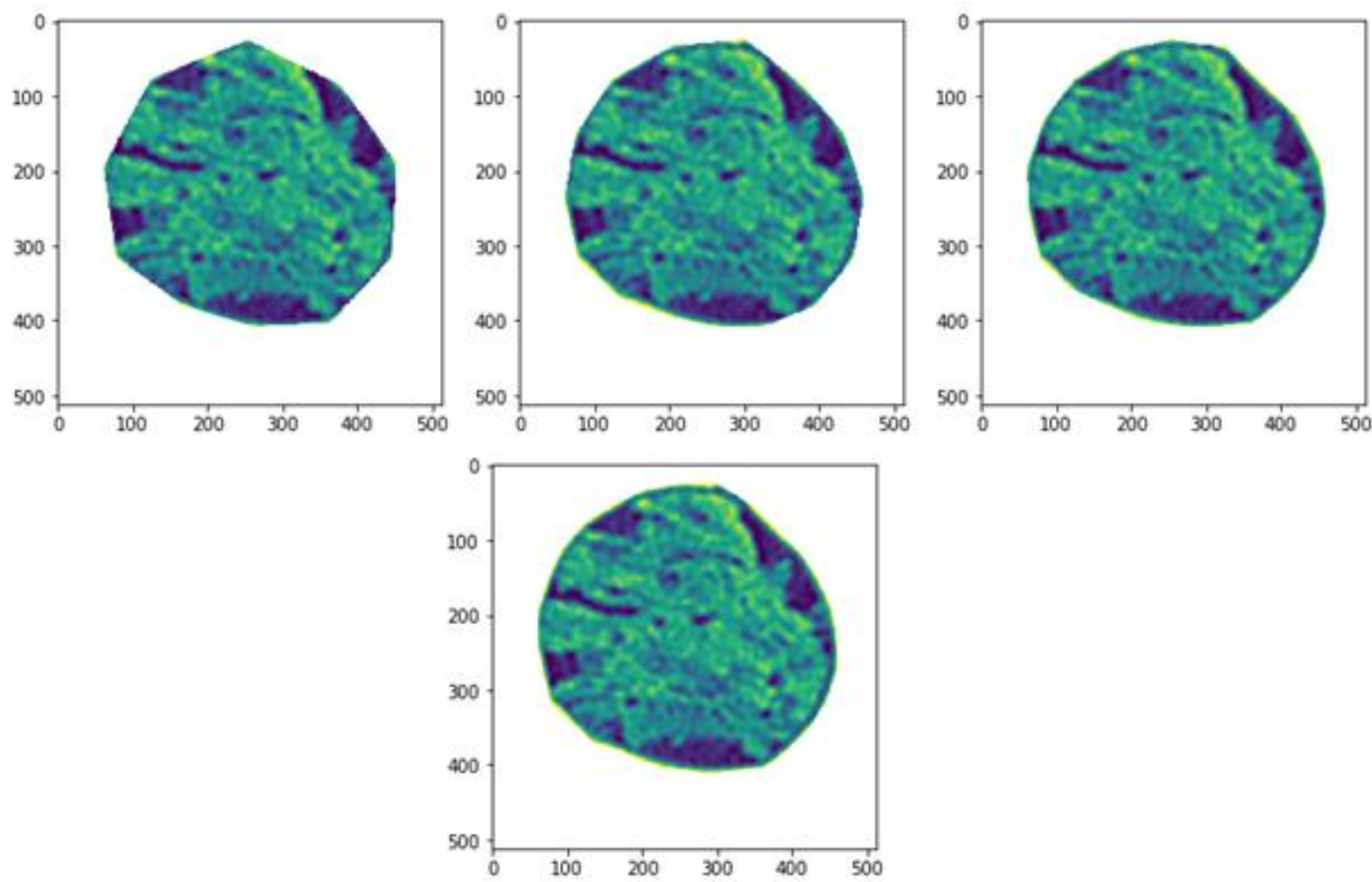

Figure 7. Image of the core after the processing, considering 10, 15, 20, and 30 angles (left to right).

proportional to the number of edges. Figure 7 shows the resulting image considering the same number of polygon edges as in the Figure 6.
If the CT value is present in the interior of the rock, it is not possible to use this methodology, because the algorithm will understand that points inside the rock belong to the border. This can be 


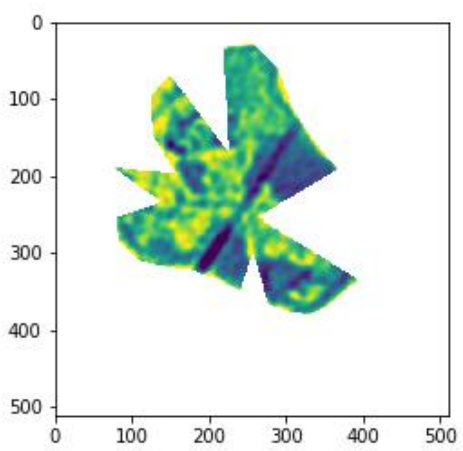

Figure 8. Example of image where the algorithm fails because high CT values are found inside the rock.

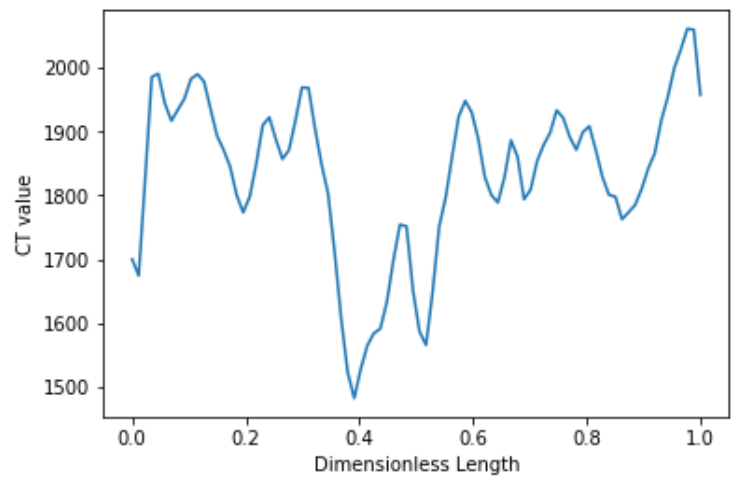

Figure 9. Average CT for the length of the core.

avoided by selecting material and fluids that lower the probability of occurrence of this problem. Figure 8 shows an example where the methodology fails.

The average CT can now be calculated from each slice image. Also, each image is stacked in a $3 \mathrm{D}$ variable to allow later 3D processing steps, such as 3D image reconstruction.

Figure 9 shows, for illustration, the average CT for the image. This information can be used for further calculations of porosity or fluid saturations (Vidal Vargas, 2015).

\section{CONCLUSIONS}

An algorithm to process CT images was proposed and developed. The implementation in Python was easy, and the libraries worked properly.
Two points demand special attention during the process:

- Since the methodology is based on CT number variations, it is important that there is a significant CT difference between rock and rubber, and that the value of CT of the rubber does not appear inside the rock.

- Pre-processing programs should not be used in the Dicom files, to ensure that no compressing is made in the image. Compressing files irreversibly damages the image and impairs the comparison of average CTs.

Once these conditions are satisfied, the algorithm can be applied, ensuring that the processing of images can be made automatically.

If the CT value is present in the interior of the rock, however, it is not possible to use this methodology, because the algorithm will understand that points inside the rock belong to the border. In these cases, methodologies that consider the core circular should be applied.

\section{ACKNOWLEDGMENTS}

The authors are grateful to the University of Campinas (UNICAMP), the Center of Petroleum Studies (CEPETRO), and the Brazilian Petroleum Agency- ANP ("Comprimisso de Investimentos com Pesquisa e Desenvolvimento") for their support to accomplish this work. The financial support of the Equinor Brasil is gratefully acknowledged.

\section{REFERENCES}

Cnudde, V.; Boone, M. N. High-resolution X-ray computed tomography in geosciences: A review of the current technology and applications. EarthScience Reviews, v. 123, p. 1-17, 2013. https://doi.org/10.1016/i.earscirev.2013.04.003

Hall, B. J.; Govert, A. Techniques for using core CT data for Facies identification and analysis. Unconventional Resources Technology Conference (URTeC). San Antonio, Texas, USA, 1-3 August, 2016. 
Honarpour, M. M.; Cromwell, V.; Hatton, D.; Satchwell R. Reservoir rock descriptions using computed tomotraphy (CT). Annual Technical Conference and Exhibition (ATCE). Las Vegas, NV, USA, 22-25 September, 1985.

https://doi.org/10.2118/14272-MS

Kak, A. C.; Slaney, M. Principles of Computerized Tomographic Imaging. New York: The Institute of Electrical and Electronics Engineering Inc., 1987.

Pydicom. Getting started with pydicom. Available at https://pydicom.github.io/pydicom/stable/getting _ started.html >. Accessed on: 2019.
Vidal Vargas, J. A. Determinação dos parâmetros de convecção-dispersão-transferência de massa em meio poroso usando tomografia computadorizada. $238 \mathrm{f}$. Doctorate Thesis. School of Mechanical Engineering and Institute of Geosciences, University of Campinas. Campinas, SP, Brazil, 2015. 